\title{
re
}

Revista Eletrônica de Ciência Política

v. 10 , n. 1 (2019), 77-90

DOI: $10.5380 /$ recp.v\%vi\%i.58439

https://revistas.ufpr.br/politica/

\section{A constituição e o papel do Estado na modernidade nas concepções de Émile Durkheim e Max Weber o processo socio-histórico e o controle social em perspectiva comparada}

ISSN: 2236-451X

\author{
Rodolfo Scotelaro Porto Darrieux \\ Doutorando, Instituto de Estudos Sociais e Políticos - IESP/UERJ
}

\begin{abstract}
O foco deste artigo é realizar uma análise comparativa acerca do Estado nacional moderno entre dois autores fundamentais na Sociologia clássica: Émile Durkheim e Max Weber. Mais precisamente, objetiva-se analisar o modo como cada autor concebe a constituição dele dentro do modo como observam o processo socio-histórico e seu papel do Estado à Modernidade caracterizada pela ascensão e consolidação do capitalismo com maior desenvolvimento da noção de indivíduo e maior conflito distributivo. Para comparar, recorri aos elementos teóricos e metodológicos nos quais os autores se fazem valer para analisar tal fenômeno histórico. Conclui-se que em Durkheim, o Estado aparece como algo necessário para a manutenção da coesão social e, em Weber, como reflexo e garantia das preferências das coletividades vencedoras ao longo do processo de transição da Idade Média para a Moderna. Porém, ambos os autores, apesar das grandes diferenças entre suas abordagens - razão pela qual foram escolhidos -, mostram que o papel do Estado envolve o controle social dos conflitos sempre potenciais na Modernidade, seja enquanto função social (Durkheim), seja enquanto monopólio da violência além de reflexo e garantia do processo de racionalização do modo de vida (Weber).
\end{abstract}

Palavras-chave: Estado, função, racionalização.

\section{INTRODUÇÃO}

"As chamadas sociedades pós-industriais tornam-se tão complexas que são obrigadas a se pensar, a se compreender a fim de se governarem. É preciso inventar-Ihes uma sociologia"

(Chêtelet et al., 1985: 321).

A passagem destacada acima aborda uma questão muito em voga nos círculos acadêmicos no século XIX e primeiras décadas do século XX: a questão da Modernidade e seus desdobramentos sociais. Refiro-me aqui às mudanças ocorridas na vida social após 
o advento e aprofundamento da industrialização, especialmente no continente europeu. Em suma, trata-se de um período muito turbulento, permeado de convulsões sociais, que caracterizou a ascensão do capitalismo e com ele, da economia de mercado. Como aponta Giddens (1990), nesse cenário as antigas tradições perderam o espaço que tiveram em períodos históricos anteriores em favor de um costume de vida e organização social que apareceram na Europa a partir do século XVIII e que se tornaram relativamente globais em termos de influência. Nesse contexto, o "eu" ganha espaço e o indivíduo passa a ser dotado de maior autonomia em escolher suas preferências e modo de vida, não seguindo necessariamente uma lógica de grupo.

Então, temos como contexto histórico sociopolítico, um ambiente no qual mudanças de uma sociedade tradicional, com base na vida comunal onde o simples fato de pertencê-la era razão suficiente para que moralmente o indivíduo tivesse o seu sustento ou proteção social garantidos, para uma capitalista na qual o risco da privação material é uma constante e o interesse individual passou a se sobrepor ao comunal devido à lógica da divisão do trabalho e ao enfraquecimento de laços tradicionais de identidade e comunidade. Nas palavras de Polanyi (2011), nesse contexto, a economia se tornou o centro da vida social e não mais algo "embebebido" na sociedade. Portanto, além da maior autonomia do "eu" como apontado acima, a competição por um espaço na divisão do trabalho se tornou uma atividade fundamental na vida dos indivíduos. Nesse cenário, a sociedade não mais garantiria as funções e subsistência de um indivíduo por questões de status social, nascimento etc. Não há formalmente algo que vá evitar o indivíduo encontrar-se em situação de escassez material, o que torna o conflito social algo sempre latente.

É nesse período que nasce a Sociologia, com a intenção de compreender essas mudanças e ordenar o mundo social. Aparecem assim, autores como Émile Durkheim e Max Weber, focos deste artigo. Aqui será feita uma análise comparativa entre os autores acerca da constituição e das atribuições do Estado nacional moderno frente ao desenvolvimento e consolidação da Modernidade, acima caracterizada pelo desenvolvimento da noção maior do "eu" e de conter maior tendência aos conflitos sociais em torno de questões distributivas (Giddens, 1990; Polanyi, 2011).

O Estado aparece na análise de ambos os autores uma vez que é uma instância organizadora e reguladora dos conflitos característicos da sociedade moderna. Desse modo, este artigo busca responder às seguintes questões: como Émile Durkheim e Max Weber encaram o Estado frente à realidade do capitalismo industrial e seus desdobramentos? Mais, precisamente, questiona-se: como ele é constituído a partir da análise que os autores fazem do processo socio-histórico e qual o papel que ele deve assumir perante essa então nova realidade e por quê? A análise de como os autores encaram o processo socio-histórico é importante ser considerada, pois aponta elementos de como suas teorias e metodologias são estruturadas além de estarem diretamente ligadas ao modo como ambos analisam o Estado. A escolha em comparar esses dois importantes autores da Sociologia reside no fato de serem bem distintos no modo de observar a sociedade e coletividades. Enquanto Durkheim encara a sociedade como uma realidade suis generis, Weber parte da ação individual e a encara como uma realidade cujas explicações são multicausais. O esquema 
abaixo sintetiza a linha de análise deste artigo:

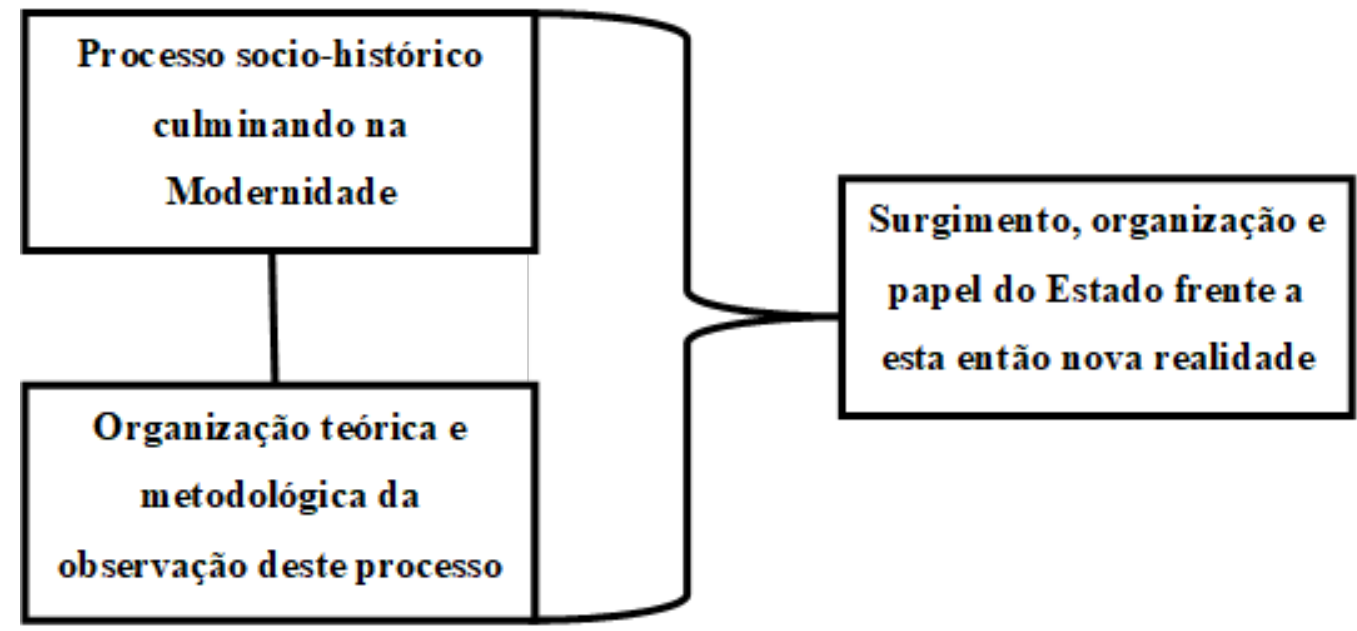

Este artigo se divide em três seções. As duas primeiras tratam do desenvolvimento da linha de análise dos autores em questão, sendo que a primeira lida com o modo como observam a Modernidade e a segunda foca na questão do Estado. Por fim, a terceira sistematiza as comparações entre as visões sendo seguida pelas considerações finais.

\section{AS ABORDAGENS DURKHEIMIANA E WEBERIANA E A QUESTÃO DA MODERNIDADE}

Nesta seção, o objetivo é mostrar os aspectos gerais das abordagens durkheimiana e weberiana e como, a partir delas, os autores entendem a formação e os principais aspectos da Modernidade - caracterizada por indivíduos com maior autonomia sobre suas identidades e maior risco de conflitos devido ao fortalecimento da disputa material em razão dos rompimentos causados no tecido social proporcionados pelo capitalismo industrial (Giddens, 1990; Polanyi, 2011) - de acordo com os dois autores em questão. Tal movimento é importante, pois desse modo é possível fazer a reflexão proposta neste artigo em torno da formação e papel do Estado nacional moderno em cada um.

Primeiramente, Durkheim argumenta que a sociedade deve ser tratada como uma realidade suis generis em que nenhum ator social propriamente a constrói. "Fatos sociais" são assim independentes das consciências individuais. Nessa linha, indivíduos são na verdade produtos da ordem dos conjunto dos "fatos sociais", o consciente coletivo. Este último, constitui em Durkheim o conjunto cultural de ideias morais que forma um sistema único com vida própria - o corpo social. Cabe destacar que, para Durkheim, a moral constitui papel central em sua teoria. A moral é o principal elemento que mantém a coesão social e evita que a sociedade se fragmente. 
Tendo isto em mente, questiona-se: como as ideias morais que constituem o consciente coletivo e os "fatos sociais" são capazes de manter a sociedade ordenada e coesa capaz de ser caracterizada como tal? Durkheim aponta principalmente em A Divisão do Trabalho Social (1978) [1893] que é através do aparato legal, ou seja, a partir do conjunto de leis que regem uma sociedade que as regras morais são impostas aos indivíduos gerando modos de interação que ele classifica como dois tipos de solidariedade: mecânica e orgânica. Nas sociedades de solidariedade mecânica, a consciência coletiva encontra-se desenvolvida de modo absoluto, ou seja, os valores e representações coletivas destas sociedades são compartilhados praticamente na sua integralidade entre os membros do grupo. Já, nas de solidariedade orgânica, há uma presença mais significativa de consciência individual em relação à coletiva. Nela, o "eu" tende a se sobrepor ao coletivo. Esta é, para Durkheim, a lógica que caracteriza as sociedades na modernidade. Já que há uma consciência individual mais robusta nestas sociedades, como a coesão social é assegurada? O que mantém os indivíduos agrupados? As leis seriam suficientes? Durkheim diz que não e encontra esta resposta na divisão do trabalho social, pois seria o âmbito no qual o indivíduo encontraria sua função social. Ou seja, é a esfera no qual o risco da privação material seria evitado além do fato da circulação da moral ser garantida uma vez que o trabalho promove a vida social do indivíduo.

É importante destacar que as dinâmicas da solidariedade mudam quando ocorre mudanças nas regras morais de interação em momentos de "efervescência coletiva"1 (Durkheim, 1978). Assim, podemos assumir que, para Durkheim, as mudanças são mecânicas e resultantes de variações nas representações coletivas ${ }^{2}$ causadas por um período de forte "efervescência coletiva" e não fruto de uma combinação de ações individuais.

Após desenvolver este raciocínio, pode-se entender a transição do período pré-moderno (solidariedade mecânica) para o moderno (solidariedade orgânica) e quais são as demais características deste último que ajuda a fundamentar a questão do Estado em Durkheim. $\mathrm{O}$ autor argumenta que o aumento das diferenciações funcionais, especialização e evolução da divisão do trabalho minaram formas tradicionais de integração moral, produzindo assim a já demonstrada solidariedade orgânica com maior grau de interdependência entre os indivíduos e uma consciência individual mais desenvolvida. Essas intensas transformações que a Modernidade gerou na vida social refletidas em crises nas representações coletivas e ideias morais tradicionais, gera um fenômeno latente: a anomia social. Este fenômeno social se caracteriza pela ausência ou conflito de valores compartilhados numa determinada sociedade. Exemplo clássico da análise empírica de

\footnotetext{
${ }^{1}$ Explicando brevemente o conceito, em As Formas Elementares da Vida Religiosa (1978) [1912], efervescência aparece como sendo uma forma de excitação, uma forma de interação que leva à exaltação, ao "aquecimento" dos sentimentos coletivos. Durkheim fala de um caráter arrebatador, que faz com que o indivíduo perceba o próprio "eu" de uma outra maneira, e que provoca uma sensação de arrebatamento. O que interessa para Durkheim neste caso, é a "efervescência coletiva", que no caso se refere a uma superexcitação gerada pela vida coletiva, ou seja, quando há interações entre os indivíduos.

${ }^{2}$ As causas que Durkheim aponta para que haja mudanças nas representações coletivas são de natureza cultural. Estas refletem o "substrato social" de períodos anteriores de uma determinada sociedade e atuam de maneira autônoma em relação aos indivíduos. De acordo com Bellah (1959), Durkheim argumenta que somente quando um determinado sistema social se encontra imerso em grandes convulsões e "fermento social", um novo sistema de ideias morais emerge e contribui com a formação de um novo sistema social. Assim, o comentarista cita como exemplo o papel de ideias de dever e moralidade cristãs como ainda atuantes nas regras morais da solidariedade orgânica.
} 
Durkheim sobre o fenômeno aparece na sua obra O Suicídio (1978) [1897], no qual o autor argumenta que no caso do suicídio anômico, tal tipo ocorre quando o indivíduo não se identifica com as normas da sociedade.

Bellah (1959) e Emirbayer (1996) argumentam que na linha de pensamento durkheimiano, tal fenômeno ocorre devido a duas variáveis: o aumento na quantidade de "unidades" que compõem a sociedade (tamanho da sociedade) e o nível de interação entre essas unidades (densidade moral). Na medida em que o tamanho e a densidade aumentam, o número de indivíduos sem especialização e envolvidos em atividades profissionais similares também aumenta. É nesse ponto que entra uma questão fundamental do pensamento durkheimiano acerca da sociedade regida pela solidariedade orgânica: o papel da divisão do trabalho nas sociedades modernas em assegurar a moral pública.

Durkheim (1978) deixa bem claro que o avanço da industrialização absorve um número cada vez maior de indivíduos para as funções econômicas, fazendo com que um montante significativo de indivíduos passem grande parte da vida no meio industrial e/ ou comercial. A forte consciência individual presente nesse cenário faz com que os indivíduos coloquem a sua função na divisão do trabalho como a centralidade de suas vidas na sociedade. Logo, a ausência da disciplina econômica e pouca diferenciação entre os indivíduos em questão profissional pode reduzir a moralidade pública. Ou seja, o autor argumenta que a vida econômica por si só é deficiente de autoridade moral, pois não garante a coesão entre os indivíduos (Emirbayer, 1996). Daí, a necessidade e a constatação de Durkheim para que ocorra cada vez mais especialização profissional de maneira que a função social dos indivíduos não seja comprometida e haja diferenciação entre eles pra que o potencial de disputa e anomia social sejam reduzidos.

No entanto, tal fator não é suficiente para que a anomia em grande escala seja evitada ${ }^{3}$. Aí entra o papel das corporações profissionais. Durkheim argumenta que na Modernidade, as corporações profissionais são fundamentais para preencher a lacuna moral que a economia por si só não consegue cumprir. Elas servem para mediar o "particularismo individualista" dos interesses econômicos na esfera pública (Emirbayer, 1996). Elas garantem a preservação moral do indivíduo frente à "lei do mais forte" das relações econômicas e o risco de anomia social generalizada característica destas relações (Durkheim, 1978: 08).

Diferentemente de Durkheim, Weber não pretende explicar, e sim compreender os fenômenos sociais ${ }^{4}$ (Châtelet et al., 1985). Na lógica weberiana, o mundo é uma realidade infinita. Nesse sentido, a sociedade não pode ser concebida como algo suis generis para o cientista social. Para Weber, o que dá ordenamento ao mundo são as ações dos indivíduos uma vez que haja conexões de sentidos entre essas ações. Assim, a ação individual constitui a centralidade da análise do sociólogo.

Uma vez que o ponto de partida em Weber é a ação individual, seu objetivo não é

\footnotetext{
${ }^{3} \mathrm{Na}$ Modernidade, a anomia possui um caráter funcional, ou seja, dentro da lógica da solidariedade orgânica, ela é sempre latente. A preocupação de Durkheim é que ela atinja tal ponto que ponha em risco a integridade do corpo social.

${ }^{4}$ Desse modo, Weber não encara o papel da Sociologia como similar às Ciências Naturais, assim como encarava Durkheim. Logo, Weber não está procurando "doenças" no "corpo social", mas sim assumindo que a Sociologia possui um objeto específico diferente das demais ciências.
} 
compreender como a coesão social surge e é garantida, e sim como coletividades podem ser constituídas a partir das ações dos indivíduos (Bendix, 1946). Uma vez pontuado que Weber trata de coletividades e não da sociedade em sua totalidade, podemos compreender que para o autor as relações entre os indivíduos constituem "pedaços" de um mundo infinito. Cabe ao sociólogo na pesquisa fazer o "recorte" para analisar essas coletivida$\operatorname{des}^{5}$ (Weber, 1978). Desse modo, em Weber, a causalidade é imputada pelo sociólogo e a partir daí, mede-se a distância de um determinado fenômeno social corresponder à imputação feita. É nessa linha de raciocínio que reside o desenvolvimento da noção de "tipo ideal", que, explicando brevemente, são noções abstratas que ajudam a reforçar padrões mais recorrentes num determinado fenômeno social estudado pelo sociólogo.

Tendo exposto os principais aspectos teóricos e metodológicos da abordagem weberiana, pergunta-se: como o autor observa o processo socio-histórico e a partir daí o surgimento e o papel do Estado na Modernidade? Bendix (1946) destaca que a ação dos indivíduos em Weber caracteriza um "fato histórico" que pode ser empiricamente observado. Por esta razão, em Weber, as coletividades não possuem nenhuma realidade fora das ações individuais desde que estas tenham sentido e reciprocidade. Uma vez que a unidade de análise é a ação individual, tanto a partir de um ponto de vista metodológico, quanto a perspectiva do mundo social, a história também é caótica e o princípio organizacional desta é a ação individual dotada de sentido por parte dos indivíduos.

Uma vez que as ações humanas assumem diferentes significados, Weber descarta explicações históricas causais totalizantes como a de Durkheim acerca da mudança da solidariedade mecânica para a orgânica. Para Weber, a especificidade da instância histórica e o modo de sua observação se for adequado irá revelar a variável de maior significância causal. Assim, não há uma causalidade específica. O "cultural" pode influenciar no "material" e vice-versa, por exemplo. Esse é um dos motivos para que no final de A Ética Protestante e o Espírito do Capitalismo (2008) [1905], Weber ter apontado também a possibilidade da ação racional relacionada a fins de ajudar a explicar o surgimento e consolidação do capitalismo ao lado da ação com relação a valores (ética protestante).

Assim como em Durkheim, cabe destacar o modo como Weber encara as mudanças sociais na história (independentemente da imputação causal levantada). A mudança da lógica do "trabalhar para viver" do Catolicismo para o "viver para trabalhar" do Protestantismo e desta para a racionalização da vida aparecem como mudanças graduais e lentas e não abruptas. É importante destacar que não só em A Ética Protestante e o Espírito do Capitalismo, Weber está voltado em entender as origens e consolidação da Modernidade $^{6}$. Em A Cidade (1966) [1921], Weber fornece uma análise muito rica do papel da cidade medieval como a principal mola propulsora do capitalismo moderno e da

\footnotetext{
${ }^{5}$ Cabe destacar que aqui Weber faz uma distinção entre "o que é" e o que "deve ser". Weber diferencia "juízo de valor" e "relação de valor", admitindo que as Ciências Sociais não podem nutrir, em seu âmbito, qualquer aspecto de avaliação moral. Sociólogos estão em relação com os valores somente na medida em que estes delimitam seu objeto em meio à multiplicidade dos fatos empíricos. Daí as aspas em "objetividade" no título de sua obra A "objetividade" do conhecimento nas Ciências Sociais [1904]. Assim, em Weber, o conhecimento sociológico deve ser axiologicamente neutro e detentor de uma metodologia que garanta o rigor e a qualidade aos resultados da pesquisa, neste caso, a utilização de "tipos ideais".

${ }^{6}$ Mais precisamente, o desenvolvimento das instituições racionais e do capitalismo industrial na Europa Ocidental.
} 
variável dependente deste ensaio, o Estado moderno, por conter ali os elementos institucionais embrionários deste já que os burgueses tinham como prática a ação racional com relação a fins, o que foi fundamental no processo de racionalização das instituições políticas, antes com base na manutenção da ordem estamental medieval, e posteriormente na dinâmica do modo de vida capitalista e sua consequente produção econômica.

Temos aí um exemplo em como que na abordagem weberiana, diversos fatores podem explicar um mesmo fenômeno (Cidade Medieval ("Portadores da prática racional") / Ética Protestante Modernidade). Por via delas, vemos que as mudanças históricas em Weber são lentas, pois na abordagem do autor, a ação dos indivíduos de uma determinada coletividade deve ir transitando de tal maneira até que haja uma consolidação institucional e social que torne tais práticas legítimas e dominantes em relação às demais coletividades.

De uma certa maneira, em todo trabalho produzido pelo sociólogo alemão, a sua preocupação principal era em torno dos fatores que produziram a Modernidade e suas características. Nesse ponto, Sell (2012) aponta que Weber organizou sua teoria da Modernidade não tanto por um aporte exclusivamente diacrônico, tendo como base a transição do tradicional para o moderno (como é o caso de Durkheim com a dicotomia solidariedade mecânica/orgânica), mas integrando a ela um procedimento essencialmente comparativo, onde a definição do moderno emerge não como uma forma civilizacional exclusiva de racionalismo, mas como uma variante contingente, ao lado de outras possibilidades históricas.

Lembrando que, em Weber, diferentemente de Durkheim, há disputa política entre os grupos sociais, ou seja, assume-se que atores políticos possuem preferências políticas distintas e se encontram em conflito, ao invés de pressupor a existência de um corpo social que deve se manter coeso para um bom funcionamento. O conflito em Weber é algo inerente ao mundo social. Assim, na lógica do autor, as mudanças graduais na história no que tange ao político são reflexos de um grupo dominando o outro. Nesse sentido, para que um grupo ou uma série deles possam se manter no poder, sua dominação precisa ser legítima perante aos outros grupos políticos e competir pelo poder no Estado, pois, o autor o conceitua como sendo uma associação política detentora do monopólio legítimo da força dentro de um determinado território. E, por sua vez, sem deter o monopólio legítimo da força, a dominação de tal grupo se encontra sob risco. Na Modernidade, diz Weber, impera a busca do lucro, ou seja, dos ganhos materiais e todos os indivíduos se encontram dentro dessa "jaula de ferro", pois as coletividades dominantes tinham tais preferências e foram as conquistando o poder político desenhando as instituições do Estado nesse sentido (burocracia racional-legal).

Tendo em mente a organização teórica, modo de transição do período pré-moderno para o moderno e principais características deste último, que podemos resumir em maior tendência às disputas materiais refletindo e atuando no processo de racionalização (Weber) e maior identidade dos indivíduos enquanto tal, podendo comprometer a coesão social e a moral pública (Durkheim) podemos passar para a análise do Estado nestes dois autores. 


\section{CONSTITUIÇÃO E PAPEL DO ESTADO MODERNO: O CONTROLE SOCIAL EM PERSPECTIVA COMPARADA}

Em Durkheim, vimos que as corporações profissionais seriam fundamentais para amenizar as tensões classistas e organizar a produção ajudando assim a garantir a moral pública e a coesão social. Elas por si só são capazes de assegurar a moral pública e, assim, a solidariedade, preservando o corpo social. Porém, Durkheim (1978) aponta que o Estado possui uma função fundamental no corpo social. Oliveira (2010) argumenta que uma vez que existem diversas corporações, há também a possibilidade de tensão entre elas. Uma vez que elas refletem a constituição de interesses distintos presentes na vida econômica frutos processo de individualização, o Estado entra com a função política de mediar esses conflitos. Ele é, então chamado então de "cérebro do corpo social".

Podemos assumir, assim, que o Estado para Durkheim aparece como uma instituição parte das dinâmicas da solidariedade orgânica. Primeiramente, temos a questão do controle da anomia sempre latente nesta então nova realidade e a necessidade de fixação de normas que orientem o comportamento econômico dos indivíduos com seus grupos. Por sua vez, é importante destacar que o Estado isoladamente não é capaz de cumprir com eficiência a sua função social. Durkheim ressalta que há uma distância considerável do Estado em relação aos indivíduos e a atividade coletiva é muito complexa para o Estado lidar por si só com ela. Portanto, ele não é capaz de diretamente penetrar na consciência coletiva.

Assim, as corporações aparecem em Durkheim como corpos intermediários na relação entre Estado e indivíduo. Desse modo, seria possível evitar a "monstruosidade sociológica" que é a relação entre uma "poeira de indivíduos desorganizados" e um "Estado hipertrofiado" (Durkheim, 1978: 19). Cabe ao "cérebro" com seus corpos intermediários aprofundar o controle social e garantir a liberdade individual ${ }^{7}$ e a moral pública. Ou seja, vemos que, em Durkheim, o Estado possui uma função social. Como aponta Lukes (1985), em Durkheim, o Estado deveria perseguir objetivos (ou fins) em acordo com as sociedades modernas, respeitando e promovendo seus valores morais. Mas, além disso, deveria liberar as "personalidades individuais", defendendo-as das antigas corporações através da criação (e promoção) dos grupos secundários de representação que se interporiam entre o nível individual e o nível do Estado. A visão de Estado aparece, então, no contexto de sua relação com os direitos individuais característicos da solidariedade orgânica e sua capacidade de garanti-los. "É quando se fortalece o Estado que a sociedade política que ele cria apresenta "uma relativa autonomia e uma força específica" (Fournier, 2007: 269 in Oliveira, 2010).

Com relação à abordagem weberiana, o primeiro ponto a considerar é que uma instituição como o Estado só pode emergir se as ações dos indivíduos forem na direção da sua perpetuação e dotada de sentido (Bendix, 1946; Spencer, 1977). Em A Cidade

${ }^{7}$ Durkheim, diferentemente dos liberais, argumenta em Leçons de Sociologie (2002) [1950] que os Direitos do indivíduo não são dados com o indivíduo e sim obra do próprio Estado. Isto ocorre pois Durkheim parte do pressuposto que o consciente coletivo precede e coage o indivíduo. 
(1966), Weber argumenta que os "portadores da atividade econômica racional" na cidade medieval eram uma classe empreendedora que permitiu o aparecimento do capitalismo racional com base na indústria. Ao lado disso, a cidade medieval facilitou a formação do Estado moderno, pois desenvolveu formas racionais de administração política e promoveu alianças políticas que aos poucos foram colocando os diferentes grupos políticos que a compunham em oposição aos elementos descentralizadores de poder e feudais (Weber, 1966; Spencer, 1977). Tal fato fica mais brevemente exposto em Política como Vocação (1982) [1919], no qual Weber esclarece que o desenvolvimento do Estado moderno é iniciado por meio da ação do soberano abrindo caminho para a expropriação dos então portadores do poder feudal para os que possuem "meios de administração próprios, meios de guerra e organização financeira, assim como os bens politicamente usáveis de todos os tipos", ou seja, para os grupos detentores do "espírito" racional (Weber, 1982: 102).

Esse processo de transição entre "tipos de dominação", por assim dizer, de um tradicional para um racional, gerou um Estado centralizado controlador dos meios totais da organização política dentro um território específico. Assim, o Estado combinou os meios materiais de organização nas mãos de suas lideranças e expropriou dos funcionários estamentais. Esse padrão é generalizável, pois é um fenômeno comum à toda Europa Ocidental e mostra que a "dominação racional" foi transitando gradualmente de um estado de ilegitimidade para o de legitimidade. Ou seja, a "dominação tradicional" foi "se racionalizando".

Bianchi (2014) argumenta que o Estado na lógica weberiana é uma condição necessária para a ordem social frente ao então novo cenário (Modernidade), que segundo Weber, está atrelada a uma busca cada vez maior pela eficiência econômica. O Estado racional e a Modernidade capitalista são dessa maneira formas homólogas. A diferença é que o Estado está limitado pela política, mas, se por ventura não atuar de modo a garantir a ordem social regida pelo cada vez maior aspecto racional da vida moderna, pode haver desordem e conflitos sociais ${ }^{8}$.

Por fim, o Estado nacional moderno em Weber aparece como resultado de ações sociais afins na lógica de uma crescente racionalização da vida e desencantamento do mundo que resultaram no seu surgimento e manutenção. Logo, diferentemente de Durkheim, ele não aparece como função, e sim como o resultado de ações individuais. Por isso, em Weber, há a dimensão do "político" no Estado, ou seja, é uma instância aberta a disputa e alianças entre grupos políticos. Os principais aspectos da sua racionalidade são: a presença das garantias legais e o funcionário de carreira. Podemos resumir o modo como Weber e Durkheim concebem o Estado moderno e suas atribuições nos seguintes quadros:

\footnotetext{
${ }^{8}$ Esse é um dos aspectos da chamada "jaula de ferro". As ações dos indivíduos na Modernidade seriam sempre no sentido da lógica racional e no constante aumento da burocratização.
} 
Quadro 1 - Durkheim

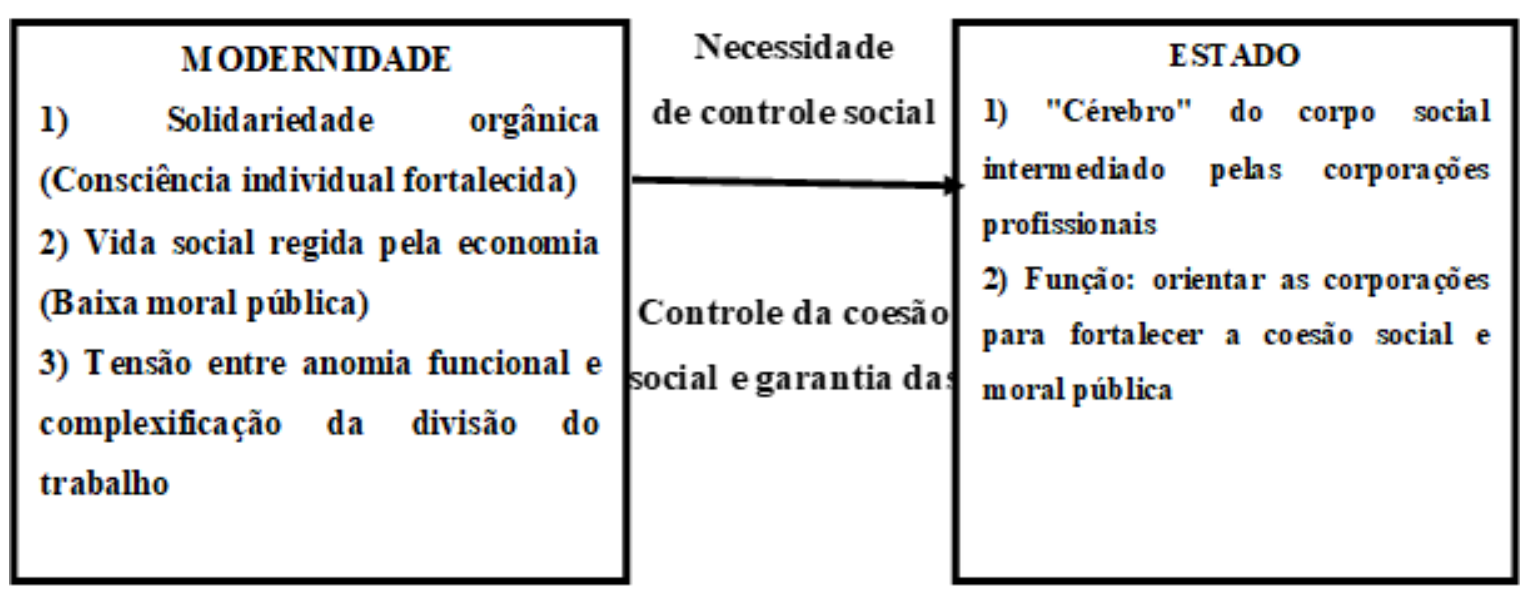

Quadro 2 - Weber

\begin{tabular}{|c|c|c|}
\hline & & DOMINAÇÃO RACIONAL- \\
\hline $\begin{array}{l}\text { DOMINAÇÃO } \\
\text { TRADICIONAL } \\
\text { 1) Estrutura descentralizad a do } \\
\text { poder (F eudos); } \\
\text { 2) "Portadores das práticas } \\
\text { racionais" gradativamente tendo } \\
\text { acesso a n noder. }\end{array}$ & $\begin{array}{l}\text { Múltịplas c ausa lid ad es } \\
\text { [Protestantismo (Valores), } \\
\text { Acúmulo de riqueza material } \\
\text { (Ac̣ão em relação a fins)] } \\
\end{array}$ & $\begin{array}{l}\text { LEGAL (MODERNIDADE) } \\
\text { 1) Desenvolimento da economia } \\
\text { capitalista (Racional); } \\
\text { 2) Estado como estrut ura centralizada } \\
\text { de poder fruto do processo de } \\
\text { racionalização (Monopólio legítimo da } \\
\text { violência / Separação entre Polític a e } \\
\text { Burocracia); } \\
\text { 3) Espaço de disputa de poder, porém, } \\
\text { preso à "jaula de ferro". }\end{array}$ \\
\hline
\end{tabular}

\section{DURKHEIM E WEBER: O ESTADO E A MODERNIDADE}

Nas seções precedentes, ficou evidente que os autores possuem muito mais diferenças do que similaridades. Certamente, um dos motivos para isto é a diferença teórica gigante acerca do modo de observação do mundo social entre ambos. Lembrando, em Durkheim, a sociedade é uma realidade suis generis e deve ser analisada e ter seus problemas diagnosticados como tais. É um "organismo" com um sistema de valores que estão acima dos indivíduos. Já Weber, é o oposto. A realidade é caótica e só passa a ter algum ordenamento na medida em que os indivíduos agem com sentido e há reciprocidade. Uma vez caótica, ela é impossível de ser apreendida em sua totalidade como fazia Durkheim, logo, cabe ao sociólogo "recortar" as diferentes realidades do mundo social. 
Em Durkheim, as mudanças sociais são mecânicas. Em Weber, são graduais através das ações dos indivíduos dotadas de sentido. Essas concepções geram resultados com mais distinções do que semelhanças acerca de uma mesma questão: O Estado na Modernidade.

Política em Durkheim é uma função social e o Estado é o órgão do corpo social que assume este papel ("Cérebro"). Como "cérebro", seu papel é fundamental para que coordenando as corporações, a coesão social seja garantida e a anomia demasiada evitada. Logo, é o principal órgão para que haja "circulação" da moralidade pública e valores para todos os indivíduos que compõem a sociedade. Em Weber, ele aparece como resultado das ações de "grupos portadores da racionalidade" e é, assim, fruto do processo de "desencantamento do mundo" e crescente racionalização. A burocracia e o aparato legal são as principais variáveis que garantem a sua racionalidade. Além disso, a dimensão do "político" em Weber é fundamental, pois é a partir do vencedor na disputa por legitimidade entre coletividades que o desenho institucional da organização política que regerá a sociedade será feito. Por sua vez, em Durkheim, esse conflito não fica evidente e o Estado aparece como um órgão do "corpo social".

No entanto, em ambos os autores, fica evidente a preocupação com os riscos de uma Modernidade desregrada como o "eu" sobrepondo o coletivo (Giddens, 1990) e "desembebida" (Polanyi, 2011) ${ }^{9}$. Em Durkheim, isto fica mais claro já que ele trata o Estado como uma função social. Em Weber, por este estar tratando o Estado moderno como um resultado do processo de racionalização, isto é menos evidente. Contudo, ao tomá-lo como a instância detentora do monopólio legítimo da violência, Weber assume que cabe ao Estado o controle social, independentemente do grupo político que esteja no poder, a fim garantir a eficiência econômica e, assim, manter a lógica do modo de vida racionalizado, regulando o conflito distributivo. Logo, ambos Durkheim e Weber assumem que, sem o Estado, as regras que garantem uma vida social menos anárquica são mais propensas de não funcionarem. A economia por si só não é o suficiente em ambos os autores para que o mundo social na Modernidade seja ordenado. Para ambos, sem o Estado, a Modernidade seria, como diria Thomas Hobbes, a "guerra de todos contra todos".

\section{CONSIDERAÇÕES FINAIS}

Neste breve ensaio, objetivei comparar como que estrutura teórica e metodológica distintas resultam em visões contendo, esperadamente, mais diferenças do que semelhanças sobre um mesmo tema através de dois autores fundamentais na Sociologia: Émile Durkheim e Max Weber. Enquanto no primeiro, o Estado moderno aparece como uma função social, no segundo, ele aparece como resultado das ações sociais dotadas de sentido. Porém, em ambos, o Estado é fundamental e aparece no objetivo de promover controle social e evitar a desordem pública, devendo regular as forças econômicas.

\footnotetext{
${ }^{9}$ Tal termo advém do conceito de disembeddedness cunhado pelo sociólogo e economista Karl Polanyi. Em breves palavras, 0 conceito indica que nas sociedades modernas, a economia sobrepõe a política enquanto que nas antigas era o contrário.
} 
Cabe ressaltar que ambos os autores são teleológicos. Enquanto Durkheim argumenta que há uma tendência a um desenvolvimento cada vez maior das corporações, sendo este processo acelerado pelo Estado, em Weber, basicamente toda imputação causal levantada tem como um mesmo resultado: desencantamento do mundo e crescente racionalização das esferas da vida, sendo o Estado um desses reflexos e também fundamental para a garantia desse modo de vida.

\section{REFERÊNCIAS}

BENDIX, R. (1946). Max Weber's Interpretation of Conduct and History. American Journal of Sociology, vol. 51, $n^{\circ} 6$, p. 518-526.

BELLAH, R. N. (1959). Durkheim and History. American Sociological Review, vol. 24, n 4, p. 447461.

BIANCHI, A. (2014). O Conceito de Estado em Weber. Lua Nova, São Paulo, nº 92, p.79-104.

CHÂTELET, F.; DUHAMEL, O.; PISIER-KOUCHNER, E. (1985). História das Ideias Políticas. Rio de Janeiro: Jorge Zahar Editor.

DURKHEIM, E. (1978). Os Pensadores. Rio de Janeiro: Editora Abril.

DURKHEIM, E. (2002) Leçons de Sociologie. Québec: L'Université de Québec.

EMIRBAYER, M. (1996). Durkheim's contribution to the Sociological Analysis of History. Sociological Forum, vol. 11, n² 2, p. 263-284.

GIDDENS, A. (1990). As consequências da Modernidade. São Paulo: Ed. UNESP.

LUKES, S. (1985). Émile Durkheim, His life and Work. Stanford University Press.

OLIVEIRA, M. (2010). O Estado em Durkheim: Elementos para um debate sobre sua Sociologia Política. Revista de Sociologia Política, Curitiba, vol. 18, nº 37, p. 125-135.

POLANYI, K. (2011). A Grande Transformação: As Origens de nossa Época. Rio de Janeiro: Editora Campus.

SELL, C. (2012). Um paradigma weberiano? Anotações sobre um programa de pesquisa. Anais do $36^{\circ}$ Encontro Anual da ANPOCS, Águas de Lindóia, 21 a 25 de outubro de 2012.

SPENCER, M. (1977). History and Sociology: An Analysis of Weber's The City. Sociology, vol. 11, $n^{\circ} 3$, p. 507-525.

WEBER, M. (2008). A Ética Protestante e o Espírito do Capitalismo. São Paulo: Companhia das 
Letras.

WEBER, M. (2011). A "objetividade" do conhecimento nas Ciências Sociais. São Paulo: Editora Ática.

WEBER, M. (1982). Ensaios de Sociologia. $5^{\text {a }}$ ed. Rio de Janeiro: Zahar Editores.

WEBER, M. (1978). Economy and Society. Los Angeles: University of California Press.

WEBER, M. (1966). The City. The Free Press.

Recebido em 27/08/2018

Aprovado em 30/11/2018

\title{
SOBRE O AUTOR
}

Rodolfo Scotelaro Porto Darrieux é doutorando em Ciência Política (IESP/UERJ). Pesquisador membro do GPPER - Grupo de Pesquisa sobre Partidos, Eleições e Representação. Lattes: http://lattes.cnpq.br/0749316303177830.

E-mail: rodolfo_scotelaro@iesp.uerj.br.

\begin{abstract}
The focus of this article is to conduct a comparative analysis of the modern national state between two key authors in classical sociology: Émile Durkheim and Max Weber. More precisely, the aim is to analyze how each author conceives its constitution within the way they observe the sociohistorical process and its role from the State to Modernity characterized by the rise and consolidation of capitalism with greater development of the notion of the individual and greater distributional conflict. To compare, I resorted to the theoretical and methodological elements in which the authors make use to analyze this historical phenomenon. It is concluded that in Durkheim, the State appears as something necessary for the maintenance of social cohesion and, in Weber, as a reflection and guarantee of the preferences of the winning collectivities throughout the process of transition from the Middle to Modern Age. However, both authors, despite the great differences between their approaches -- the reason why they were chosen --, show that the role of the State involves the social control of the always potential conflicts in Modernity, either as a social function (Durkheim), or as a monopoly of violence besides reflection and guarantee of the process of rationalization of the way of life (Weber).
\end{abstract}

Keywords: State, function, rationalization.

Resumen: El objetivo de este artículo es realizar un análisis comparativo del estado nacional moderno entre dos autores claves de la sociología clásica: Émile Durkheim y Max Weber. Más precisamente, se trata de analizar cómo cada autor concibe su constitución dentro de la forma en que observa el proceso socio-histórico y su papel desde el Estado hasta la modernidad, caracterizado por el surgimiento y consolidación del capitalismo, con un mayor desarrollo de la noción de individuo y un mayor conflicto distributivo. Para comparar, recurrí a los elementos teóricos y metodológicos en 
los que los autores se sirven para analizar este fenómeno histórico. Se concluye que en Durkheim, el Estado aparece como algo necesario para el mantenimiento de la cohesión social y, en Weber, como reflejo y garantía de las preferencias de las colectividades ganadoras a lo largo del proceso de transición de la Edad Media a la Moderna. Sin embargo, ambos autores, a pesar de las grandes diferencias entre sus enfoques, por lo que fueron elegidos, muestran que el papel del Estado implica el control social de los siempre potenciales conflictos de la modernidad, ya sea como función social (Durkheim), ya sea como monopolio de la violencia más allá del reflejo y garantía del proceso de racionalización del modo de vida (Weber).

Palabras clave: Estado, función, racionalización. 